\title{
Calvyn en die Heidelbergse Kategismus
}

\author{
L.F. Schulze \\ Dept. Dogmatologie en Ekklesiologie \\ TSP / Potchefstroomse Universiteit vir CHO \\ POTCHEFSTROOM
}

\begin{abstract}
To ascertain the influence of Calvin on the Heidelberg Catechism has been complicated by at least three circumstances: (1) Olevianus' acknowledgement that the catechism was the work of many pious people from Suitzerland: (2) the fact that many facets of the Catechism's content were common currency during the loth century; (3) the obvous independence of the Reform movement in the Palitinate. In this article it is argued that the typical Calvinian accent on the three-fold office of (hrist as reflected in the Heidelberg Catechism is perhaps the clearest example of Calvin's influence. Yet even in this respect the Heidelberg Catechism retains its ow'n character by condensing ('alvin's exposition of the triplex munus in his Genevan Catechism.
\end{abstract}

\section{Die probleem}

Op 14 April 1563 het Olevianus aan Bullinger 'n brief geskryf waarin hy sè: 'Nie die vroom gedagtes van één mens nie, maar van baie is daarin (in die Heidelberse Kategismus) byeengebring'. Hy voeg daaraan toe: 'Sekerlik, as daarin ' $n$ bepaalde duidelikheid te vind is, het ons dit grootliks aan jou en die helder geeste van Switserland te danke' ( $O C,{ }^{1} 19.683$; Neuser, 1979:181; Engelbrecht, 1989:632).

Bogemelde sinne uit die brief van Olevianus toon duidelik die moeilikhede wanneer die onderwerp van Calvyn en die Heidelbergse Kategismus aan die orde moet kom. Eerstens blyk uit die brief die selfstandigheid en veelkleurigheid van die reformasie in die Palts wat in die Heidelberse Kategismus neerslag vind ("nie die gedagtes van één mens nie, maar van baie'). Tweedens word die invloed van die Switsers erken. Olevianus het hierby waarskynlik aan die invloed van Bullinger en Calvyn gedink. Dis egter moontlik dat hy ook aan die invloed van ander Switsers gedink het. Hy praat immers in die meervoud 'van jou en die helder geeste van Switserland'. Dit is bekend dat die opstellers van die Heidelbergse

I

$O C$ verwys na Opera Calvini

In die Skriflig 27(4) 1993:487-499 
Kategismus, benewens andere, nie net die kategismusse van Bullinger en Calvyn geraadpleeg het nie, maar ook die twee Zürichse kategismusse van Leo Judae (Engelbrecht, 1989:632; Goeters, 1963:13-14; Hollweg, 1961:87; Neuser, 1979: $181)$.

Die brief van Olevianus belig gevolglik reeds iets van die veelkantigheid van die probleem wat opduik wanneer Calvyn se invloed op die Heidelberger nagespeur moet word.

Enkele verdere kante van die probleem word vervolgens genoem. Daarna word 'n paar aspekte van die probleem kortliks toegelig en die implikasies van die probleem na vore gebring. Tweedens sal 'n uitweg uit die probleem gesoek word en aan die hand hiervan ' $n$ voorbeeld gegee word van moontlik tipies Calvynse invloed op die Heidelberger.

\section{Die veelkantigheid van die probleem}

Naas die relatiewe selfstandigheid van die Reformasie in die Palts en die erkenning van Switserse invloed op die Heidelberger, moet derdens nog ' $n$ kant van die probleem genoem word: die feit dat die formulerings in die kategismusse van die sestiende eeu in die meeste gevalle insigte wat eie aan die hele Reformasie was, na vore bring. Eersgenoemde en laasgenoemde aspek word vervolgens kortliks belig.

\subsection{Selfstandige reformasie in die Palts}

\subsubsection{Frederik III (1515-1576)}

Frederik III het met die Bybel geleef en die Woord ondersoek omdat dit vir hom die enigste rigsnoer vir die geloof was. Dit was deur sy eie Skrifstudie dat hy van die korrektheid van die gereformeerde (Switserse) manier van Nagmaalviering oortuig geraak het. Herhaaldelik het hy gestel dat hy in der waarheid die geskrifte van Zwingli en Calvyn nie gelees het nie, omdat hy nie sy geloof op die gesag van 'n mens wou begrond nie (Hollweg, 1961:18). Direkte invloed van Calvyn op Frederik III en deur laasgenoemde op die ontstaan van die Heidelbergse Kategismus kan gevolglik nie aangetoon word nie.

\subsubsection{Ursinus (1534-1583)}

Ursinus was sewe jaar lank student van Melanchthon en tussen hulle het 'n hegte vriendskapsband gegroei. Later het hy egter 'n oortuigde navolger van Calvyn geword (Steenkamp, 1989:615-616; Neuser, 1979:180; Polman, 1961:439). Dit is bekend dat Ursinus ' $n$ baie belangrike aandeel aan die ontstaan van die Heidel- 
berger gehad het. Dit was immers aan hom dat die Keurvors opdrag gegee het om twee ontwerpe voor te lê waarop die kommissie wat die kategismus moes opstel, verder kon bou (Goeters, 1963:12; Oberholzer, 1986:2; 1989:600). Sedert die baanbrekerswerk van August Lang staan die twee ontwerpe van Ursinus as die Catechesis Maior en die Catechesis Minor bekend. Die kommissie het veral by die Minor aangeknoop. Neuser (1979:179) sê van die Minor: "In ihm liegt der Heidelberger Katechismus schon etwa im halben Wortlaut fest."

Nou is dit voor die hand liggend om Calvyn se invloed op die Heidelbergse Kategismus te sien as iets wat deur die leeue-aandeel van Ursinus bewerk is. Ursinus was immers ' $n$ uitgesproke Calvinis. Tog is Calvyn se invloed ook in hierdie geval nie so reglynig as wat dit mag lyk nie. Eerstens kan genoem word dat Neuser (1979:179) op grond van teologiese verskille tussen die Maior en die Minor twyfel of laasgenoemde die werk van Ursinus is. Hy sluit hom dus in sy opvatting by Lang aan, wat meen dat die Minor nie Ursinus se skepping was nie maar reeds 'n oefenlopie van die kommissie. (Die enigste 'bewys' dat die Minor Ursinus se werk was, lê in die feit dat dit na sy dood in sy biblioteek in sy eie handskrif gevind is - iets wat nie afdoende bewys van outeurskap is nie omdat Ursinus ook die besluite van die kommissie kon bygehou het.) Maar ook al is die Minor Ursinus se voorlegging, lê daar nog teologiese gapings tussen die Minor en die Heidelberger wat aandui dat daar ook ander invloede op die Heidelberger as dié van Calvyn ingewerk het.

Ter illustrasie van hierdie aspek word slegs een voorbeeld genoem. Die predestinasieleer was vir Calvyn 'n Bybelse leer wat vir die troos en opbou van die kerk onontbeerlik was. Wanneer Bolsec in 1552 die predestinasieleer kritiseer en dit 'n slegte reuk wil gee, verkry Calvyn van die Raad van Genève sy verbanning uit die stad. Hierdie insident word ook die aanleiding om finaal met Pighius (oorl. 1543) en sy kritiek op die predestinasieleer af te reken - al is dit nege jaar na sy dood! So ontstaan die traktaat De aeterna praedestınatione Dei (Schulze, 1971: 19). In die Institusie vorm die predestinasieleer ook die sluitstuk van die verlossing wat vas lê in die ewige welbehae van God (Inst. 3.21-24). In die Minor vind hierdie tipiese aksent van Calvyn weerklank. In aansluiting by die regverdigingsleer (vr. 46-48) en by die vraag na die herkoms van die geloof (vr. 49) word in vraag 50 dan (in die belydende ek-vorm) van die uitverkorenes en die massa verworpenes (multitudo reproha) gewag gemaak. In dieselfde asem word gesê dat die uitverkiesing vóór die grondlegging van die wêreld in Christus plaasgevind het (vgl. Neuser, 1979:191). Die opvallende is egter dat die Minor se tipies Calvynse aksent op die predestinasie in die finale gestalte van die Heidelbergse Kategismus afwesig is. Die uitverkiesing kom slegs een keer sydelings in verband met die kerk ter sprake: "n gemeente wat tot die ewige lewe uitverkies is' (S.21, vr. 54), terwyl die ander pool van die predestinasie, naamlik die verwerping, ontbreek. Hieruit blyk dat Ursinus nie 'n vry hand in die opstelling van 
die Heidelbergse Kategismus gehad het nie. Waar Ursinus in sy ontwerp die aksent wat Calvyn in sy Institusie en traktate op die predestinasie gelê het, verdiskonteer, het die kommissie hom hierin nie gevolg nie maar waarskynlik Calvyn se Geneefse Kategismus gevolg, waar die uitverkiesing slegs in vraag 101 (Calvyn, 1981:21) in verband met die kerk ter sprake kom. Daarom moet vervolgens na die kommissie wat die Heidelberger sy finale vorm gegee het, gekyk word.

\subsubsection{Die kommissie}

In sy voorrede by die eerste uitgawe van die Heidelbergse Kategismus sê Frederik III dat die jeug van sy keurvorstedom tot op daardie stadium in kerke en skole op ' $n$ baie nalatige wyse opgevoed en onderrig is en dat hy aan die lukraak onderwys 'n einde wil maak en die noodsaaklike onderrig van die jeug op vaste voet wil plaas. Dan vervolg hy (Oberholzer, 1986:17):

Ons het dit dus hoogs noodsaaklik geag om hieraan, as die belangrikste element van ons regering, behoorlik aandag te gee, die verkeerdheid en ongelykheid af te skaf en noodsaaklike verbetering aan te bring

Daarom het ons met die advies en medewerking van ons hele teologiese fakulteit alhier en ook van alle superintendente en die belangrikste kerklike ampsdraers, 'n samevattende onderrig of kategismus van ons Christelike godsdiens uit die Woord van God laat opstel en vasstel, in Duits sowel as Latyn (oorspr. Duitse teks in Niesel, 1948:139).

Wie die lede van die 'teologiese fakulteit' was, kan met sekerheid gesê word. Moeiliker bepaalbaar is die lede wat onder die 'belangrikste kerklike ampsdraers' gereken moet word, asook wat die rol van die nege superintendente van die Palts was. Volgens Neuser (1979:178) het die superintendente slegs aan die finale sinodesitting van 12 tot 18 Januarie 1563 meegewerk. Met sekerheid kan gesê word dat die drie professore van die teologiese fakulteit, naamlik die Italiaanse Jood Tremellius, die Fransman Boquinus en die Silesiër Ursinus op die kommissie was. Hoogs waarskynlik was Olevianus, die hofprediker Diller en die teologies onderlegde lyfarts van die Keurvors, naamlik Erastus ook aanwesig. Moontlik was Dathenus ook daar. Verder is uit die briefwisseling van Frederik 111 duidelik dat ook hy aan die opstel van die Heidelberger meegewerk het (Kluckhohn, 1868:465, 726, in Neuser, 1979:178). Hienuit is dit duidelik dat die Heidelbergse Kategismus, soos Olevianus in sy brief aan Bullinger sê, nie die werk van één man was nie maar van baie.

Die teologiese oriëntering van die (waarskynlike) samestellers was soos volg: Ursinus, Olevianus, Tremellius, Boquinus en Dathenus was Calviniste; Diller was 'n navolger van Melanchthon en Erastus was 'n Zwingliaan. Die vraag ontstaan dus waar die Keurvors geplaas moet word. Was hy 'n 'onafhanklike' met sterk neigings na die Switserse Nagmaalsopvatting wat terselfdertyd deur Melanchthon 
geadviseer is? Het hy op beslissende punte 'n deurslaggewende rol gespeel? Helaas ken ons nie die antwoorde op hierdie vrae nie omdat die acta van die kommissie en die sinode deur oorloè verlore gegaan het.

Dit is in ieder geval duidelik - soos uit die bostaande voorbeeld van die uitverkiesing aangetoon is - dat die Calviniste, ofskoon in die meerderheid, nie bloot die visie van Calvyn op die Heidelberger afgedruk het nie. Die Heidelberger was eerder die vrug van gemeenskaplike arbeid en konsensus van die kommissielede met hulle verskillende teologiese aksente.

Daarom het navorsers van die teologiese aard en gehalte van die Heidelbergse Kategismus (miskien elk met 'n tikkie vooringenomenheid) tot teenstrydige konklusies gekom. Heppe het byvoorbeeld gemeen dat die Heidelberger duidelik die trekke van Melanchthon se teologie openbaar. Gooszen daarenteen het gesê dat die werk 'n laat-Zwingliaanse aard het omdat die oorwegende invloed van Bullinger daarop aangetoon kan word. Lang het die vorige opvattings verwerp en getrag om die deurslaggewende invloed van Calvyn op die Heidelberger aan te toon (vgl. Neuser, 1979:180).

'n Mens sal waarskynlik moet konkludeer dat al drie hierdie gedeë navorsers tot 'n mate reg is omdat die Heidelberger elemente van al drie Reformatore bevat. Daarby het Hollweg (1961:86 e.v.) getrag om die invloed van Beza, veral van sy Confessio brevis, op die Heidelbergse Kategismus aan te toon, terwyl Neuser (1979:181-182) selfs enkele gevalle aantoon (vr. 34, 24 en moontlik vr. 1) waar Luther se Klein Kategismus weerklank vind.

\subsubsection{Die sinode}

Die kommissie het die kategismus saamgestel. Daama het die ontwerp nog deur die hande van 'n sinode gegaan! Engelbrecht $(1989: 631,632)$ teken die situasie soos volg:

Toe die konsep in Januarie 1563 gereed was, het Frederik dit voorgelê aan 'al my superintendente, vernaamste kerkdienaars en teoloễ en vir agt dae het hierdie sinode gedagtes gewissel en die Kategismus met God se Woord en met ander geskrifte uit die kerkhervorming vergelyk'... Op 17 Januarie 1563 het die sinode van die Palz die heilige nagmaal gevier, ook met die oog op 'die meerdere eenstemmige bevestiging van die Kategismus'. Daarna het Frederik die sinode toegespreek en gewag gemaak van sy blydskap oor die eenstemmigheid wat gevoer het tot 'n eenvormige Kategismus wat nou kon dien tot die opbou van die geloof van sy onderdane en as basis vir die burgerlike welvaart van sy land en regering. 


\subsection{Reformatoriese gemeengoed}

'n Tweede verswarende omstandigheid om Calvyn se invloed op die Heidelbergse Kategismus te bepaal lê in die feit dat baie Skriftuurlike insigte en fonnuleringe gemeengoed van die Reformasie was. Baie voorbeelde hiervan kan na vore gebring word. Hier word egter met 'n enkele voorbeeld volstaan: Luther se aksent op die pro nobis van God se bemoeienis soos in die evangelie aangekondig.

Die gedagte dat God 'vir ons is', word duidelik verwoord in die Pauliniese oorwinningslied: "As God vir ons is, wie kan teen ons wees?" (Rom. 8:31). Dit is interessant om te sien hoe Luther reeds in die eerste roersels van die Reformasie, naamlik in sy Vorlesung über den Römerbrief van 1515-1516, in die rigting van God se genadige bemoeienis met ons beweeg. Hierdie beweging is verbind met sy nuwe insig in die betekenis van die "geregtigheid van God", waarvan Paulus in Romeine 1:17 gewag maak. Die nuwe insig van Luther hou in dat hy nie meer die uitdrukking "geregtigheid van God" wat in die evangelie geopenbaar is (Rom. $1: 17$ ), verstaan as eienskap van God nie maar as 'n gawe waardeur Hy ons regverdig maak. Hy sê:

Want die geregtigheid van God is die oorsaak van die heil. En hier mag mens weer onder die 'geregtigheid van God' nie daardie geregtigheid verstaan waardeur Hy in Homself regverdig is nie, maar waardeur ons uit Hom geregverdig word. Dit geskied deur die geloof in die evangelie" (WA 56:172).

Calvyn beklemtoon reeds aan die begin van sy Institusie dat kennis van God geen abstrakte kennis is nie maar eerder ' $n$ oortuiging "dat Hy die bron van alle goed is en dat ons niks elders as net in Hom moet soek nie" (Inst. 1.2.1). Daarom verwerp hy die Skolastiek se vraag na die Wese van God ("Wat is God" - die vraag waarmee Thomas sy Summa begin!) as koue spekulasie en sê dat dit vir ons baie belangriker is "om te weet wat sy hoedanighede is en wat by sy natuur pas. Want wat baat dit om saam met Epikuros 'n God te bely wat alle sorge vir die wêreld laat vaar het en net maar in ontspanning behae skep? Kortom: wat help dit ons om 'n God te ken met wie ons niks te doen het nie?", vra Calvyn (Inst. 1.2.2). ${ }^{3}$

2 WA venuss na Luther, 1912 D Martin Luthers Werke Kritische Gesamtausgabe

3 Afrikaanse vertalings van dic Insfifusie is dié van HW. Simpson, 1984, 1986 en 1988 Institusie van die Christelike godsdiens (I559). Bock 1, 2 cn 3. 
Die Geneefse Kategismus (1541; Lat. 1545) begin met dieselfde invalshoek. Vraag 1 lui:

Leraar $(=\mathrm{L})$ : Wat is die belangrikste doel van die mens se lewe?

Seun $(=\mathrm{S})$ : Om God deur wie die mens geskape is te leer ken (Calvyn, 1981:5).

Ware en egte kennis van God is "wanneer Hy so geken word dat die eer wat aan Hom verskuldig is, aan Hom betoon word" (vr . 6). Dit gebeur (eerstens) wanneer ons ons vertroue ten volle in Hom stel (vr. 7) en hierdie vertroue is gegrond in die kennis van God in Christus (vr. 14), waarvan die kern in die Twaalf Artikels saamgevat word (vr. 15). Binne hierdie konteks kom die vraag na die nut van die kennis vir ons, soos in die Heidelberger, telkens ter sprake. 'n Mooi voorbeeld daarvan is geformuleer in vraag 40. Nadat daar gehandel is oor die Naam Christus, en sy salwing tot Koning, Priester en Profeet aan die orde gekom het (vr. 3439), volg die vraag (Calvyn, 1981:11):

L: Maar pluk jy die vrugte daarvan?

S: Welseker; dit alles is trouens op niks anders gerig as op ons seën nie. Want dit is deur die Vader aan Christus gegee sodat Hy dit met ons kan deel en ons almal uit die volheid daarvan kan put.

In die Heidelbergse Kategismus weerklink die nut van die kennis pro nobis ook telkens. Engelbrecht (1989:633-634) som dit mooi op:

Tipies en opvallend van die Heidelbergse Kategismus is die pro nobis toonaard daarvan, die gekonsentreerde toespitsing van die heilsbetekenis van ' $n$ bepaalde leerstuk op die 'my' van die katkisant. Die heilsfeite, byvoorbeeld dat God die Almagtige, die Skepper van hemel en aarde is (26), of dat Jesus Christus wat werklik dood was, opgestaan het en lewe (45), word as 't ware stilswyend aanvaar, maar die heilsherekenis word gekonsentreerd toegespits op die 'vir my' van die katkisant. Heidelbergse Kategismus vra gewoonweg: 'Watter nut het die opstanding van Jesus Christus vir ons?' Die antwoord lui dan: 'Eerstens het Hy deur sy opstanding die dood oorwin sodat Hy ons die geregtigheid wat Hy deur sy dood verwerf het, deelagtig kon maak. Tweedens word ons nou ook deur sy krag tot ' $n$ nuwe lewe opgewek. Derdens is die opstanding van Christus vir ons 'n betroubare waarborg van ons salige opstanding.

Engelbrecht vergelyk in sy artikel die Heidelbergse Kategismus met die Nederlandse Geloofsbelydenis. Wanneer hy dus praat van "tipies en opvallend van die Heidelbergse Kategismus is die pro nobis toonaard daarvan" geld dit slegs die vergelyking met die Nederlandse Geloofsbelydenis. Daarmee is dus nie gesê dat die "pro nobis toonaard" net eie aan die Heidelbergse Kategismus is nie. 
Die gemeenskaplike aksent van die Reformatore op die heilsbetekenis van God se dade lê ingebed in die aard van die Reformasie as beweging wat veral op die heilstoeeiening toegespits was. Daarom kan voorbeelde van gemeenskaplike aksente en selfs van gelykluidende formulerings in baie geskrifte van die Hervormers aangetoon word. Naas die enkele lyne wat hierbo in dié verband getrek is, word nog slegs verwys na die gemeenskaplike aksente van Luther, Calvyn en die Heidelberger se verklaring van die Eerste Artikel. Dit is opvallend dat die geloof in God die Vader, die Skepper van hemel en aarde, direk verbind word met sy voorsienige sorg en vaderlike goedheid (Luther, 1919:78; Calvyn, 1981:8-9; HK, vr. 26, 27; vgl. Schulze, 1991:21-22).

J.M. Reu, die uitnemende kenner van die kategetiese literatuur van die Reformasie, het die saak van gemeenskaplike insigte duidelik opgesom:

Manche Ausführungen in den katechetischen Schriften dieser Zeit waren Gemeingut der ganzen evangelischen Kirche (Reu, 1904:201, in Hollweg, 1968:42; vgl. ook Hollweg, 1961:87).

\subsection{Afleidings}

Dit is duidelik dat die bepaling van invloede op die Heidelbergse Kategismus 'n gekompliseerde saak is. Selfs waar twee dokumente dieselfde woorde gebruik, is dit nog geen afdoende bewys van direkte invloed van die een op die ander nie; dit kan immers ook te danke wees aan algemene insigte wat eie aan die Refonnasie as geheel was (kyk vir voorbeelde Hollweg, 1968:43-45).

Invloede op die Heidelberger (van byvoorbeeld die eerste geslag Hervormers én van ander kategismusse) was van indirekte aard. Die invloed (ook dié van Calvyn) moes deur minstens twee 'filters' gaan, naamlik dié van die kommissie wat die Heidelberger ontwerp het, en dié van die sinode wat dit goedgekeur het.

Hierdie toedrag van sake bemoeilik die bepaling van invloed op die Kategismus. Terselfdertyd was dit egter ook die rede waarom die Heidelbergse Kategismus geen aaneengerygte lappieskombers is nie maar ' $n$ unieke skepping met ' $n$ eie skoonheid en helderheid wat in die komende eeue sy triomfe sou vier.

\section{3. 'n Moontlike uitweg}

\subsection{Tipies Calvynse aksente}

Die enigste moontlike uitweg uit die probleem sou wees om eerstens te kyk of daar bepaalde aksente van Calvyn is wat eie aan hom is en nie by ander Hervormers voorkom nie en of sodanige tipiese aksente in die Heidelberger neerslag gevind het. Hierdie uitweg word deur Neuser (1979:181) as die teologies- 
historiese metode getipeer as hy sê: "Die theologiegeschichtliche Methode ist erst am Ziel, wenn auf Grund der Einzelaussagen die Gestalten der einzelnen 'Väter' sichtbar werden".

Hiermee saam moet tweedens gekyk word hoe die tipiese teologiese aksente van Calvyn in die Geneefse Kategismus geformuleer word en of die Heidelberger die bepaalde fonnuleringe ooglopend oorneem. Hier stuit ' $n$ mens soms op die omstandigheid dat 'n insig eie aan Calvyn deur die Heidelberger oorgeneem word maar tog anders geformuleer word as in die Geneefse Kategismus. 'n Mens sou hier nog van Calvyn se invloed kan praat maar moet tog die indirekte aard daarvan raaksien omdat sodanige insig van Calvyn deur die 'filter' van die teologies selfstandige kommissie gegaan en deur hulle oorgeneem is omdat hulle dit as Bybels verantwoord beskou het. Immers, die Heidelbergse Kategismus is só ' $n$ oorspronklike skepping dat daar nêrens daarin enige spoor van 'n sito-sito plagiaat gevind word nie.

Navorsers wys op die uiteensetting van Christus se drievoudige amp as 'n insig wat duidelik van Calvyn afkomstig is. Neuser (1979:184) sê:

Insbesondere hervorzuheben ist das dreifache Amt Christi nach Frage 31; die Lehre vom triplex munus Christi stammt überhaupt von Calvin, der als erster dem königlichen und hohepriesterlichen Amt das prophetische beigefugt hat (vgl. ook Müller, 1900:734).

Die vraag is egter of Calvyn met sy siening van die triplex munus Christi heeltemal oorspronklik was. Daar is aanduidings dat daar minstens presedente was sover dit dié opvatting betref. In sy Franse uitgawe van die Institusie merk Benoit (1957:267, verw. 8) op dat die gedagte reeds by Eusebius (Hist. eccles. 1.3.9) voorkom en stel die moontlikheid dat Calvyn die gedagte oorspronklik by Bucer gekry het ${ }^{4}$. Terloops, dit is interessant om op te merk dat Thomas ook 'n opmerking in hierdie verband gemaak het:

Christus is volmaak in alle gawes, en daarom is $\mathrm{Hy}$, in soverre dit andere aangaan. Wetgewer, Priester en Koning; maar dit alles_kom in Christus byeen (Summa Theol. 3.22.1, in Calvyn, 1986:648, verw. 2).

Hoe dit ook al sy, dit is duidelik dat Calvyn die teoloog was wat die leer van die drievoudige amp breêr uitgewerk het. Dit verskyn vir die eerste keer in die tweede uitgawe van die Institusie (1539) - juis toe Calvyn in Straatsburg was! - en word breed uitgewerk in Boek 2, hoofstuk 15 van die finale uitgawe (1559). In

$4 \quad \mathrm{Vg}$ ! Bucer se Ennar. in Evang., 1536.607 Rex regum Chnstus est, summus sacerdos, et prophetanum caput. 
die Geneefse Kategismus kom die drievoudige amp weer uitvoerig in vrae 34-45 ter sprake in verband met die naam Christus (Calvyn, 1981:10-12).

'n Tweede tipies Calvynse gedagtegoed is die verklaring van Christus se neerdaling na die hel (vgl. Inst. 2.16.8; GK, vr. 66-71 - Calvyn, 1981:15-16). Hierdie verklaring vind weerklank in vraag 44 van die Heidelbergse Kategismus.

\section{2 'n Voorbeeld}

Om die invloed van Calvyn op die Heidelbergse Kategismus te illustreer sal die Geneefse Kategismus se uiteensetting van die triplex munus met dié van die Heidelberger vergelyk word. Die Geneefse Kategismus behandel die drievoudige amp van Christus in nie minder as twaalf vrae nie (Calvyn, 1981:10-12).

34. L: Wat is verder die betekenis van die woord Christus?

S: Met hierdie benaming word selfs nog beter uitdrukking gegee aan sy amp. Want dit dui aan dat Hy deur die Vader gesalf is tot Koning, Priester en Profeet.

35. L: Hoe weet jy dit?

S: Omdat die Skrif salwing onder hierdie drie eienskappe tuisbring. Verder skryf dit dikwels hierdie drie waarvan ons melding gemaak het, aan Christus toe.

37. L: Wat is dan die aard van sy koninkryk ${ }^{5}$ wat jy vermeld?

Dit is 'n geestelike koninkryk, wat in die Gees van God en in sy Woord vervat is en geregtigheid en die lewe teweegbring.

38. L: Wat van sy priesterskap?

S: Dit is sy amp en voorreg om voor die aangesig van God te staan om genade te verkry en deur 'n offer te bring wat vir Hom behaaglik is, sy toom te versoen.

39. L: In watter betekenis noem jy Christus 'n Profeet?

S: Want toe Hy na die wêreld neergedaal het, het Hy Homself as gesant en middelaar van die Vader geopenbaar. Die doel daarvan was om die wil van die Vader ten volle te verduidelik en 'n einde aan al die openbaring en die profete te maak.

In Frans Royaume (Niesel, 1948:6). In Afrikaans is Koningskap bcter in hierdie verband 
Vraag 40 is reeds vroër aangehaal. Vraag 41 vra 'n nadere verduideliking van die vorige vraag, waarop die antwoord kom:

Hy is vervul met die Heilige Gees, en bekroon met die volmaakte rykdom van al sy gawes sodat $\mathrm{Hy}$ aan elkeen van ons na sy maat kan skenk wat die Vader weet by ons pas. So put ons uit Hom soos uit ' $n$ unieke bron al die geestelike seëninge wat ons het.

Dan volg daar nog drie vrae oor die voordeel wat sy koning-, priester- en sy profeetskap vir ons inhou en 'n samevatting deur die Leraar waarop die Seun bloot antwoord: "Ja, dit is so" (vr. 45).

Die drie vrae word vervolgens aangehaal.

42. $\mathrm{L}$ : Watter voordeel het sy koninkryk vir ons?

S: Dit naamlik dat ons deur sy goedertierenheid van ons gewete bevry is om vroom en heilig te lewe, en deur sy geestelike rykdom toegerus is en ook deur sy mag bewapen word. Dit is vir ons genoeg om die ewige vyande van ons siele, naamlik die sonde, ons vlees, die Satan en die wêreld te oorwin.

43. L: Waartoe lei sy priesterskap?

S: In die eerste plek, dat Hy om hierdie rede ons Middelaar is om ons met die Vader te versoen; tweedens dat $\mathrm{Hy}$ vir ons 'n toegang tot die Vader geopen het sodat ons met vertroue tot sy aangesig kan nader en onsself en alles wat ons het aan Hom kan offer. So maak Hy ons op die een of ander wyse deelgenote in sy priesterskap.

44. L: Nou bly daar nog sy profeetskap oor.

S: Aangesien die gawe van onderwysing van die mense wat aan Hom behoort aan die Seun van God opgedra is, is die doel daarvan dat Hy dié mense met die ware kennis van die Vader moet verlig, hulle in sy waarheid moet onderwys en van hulle dissipels in die huis van God moet maak.

Daar is opsetlik breedvoerig uit die Geneefse Kategismus aangehaal om die betogende trant van Calvyn met die bondigheid van die Heidelberger te kontrasteer. Laasgenoemde vat die essensie van die Geneefse Kategismus in twee vrae saam. In vraag 31 is die betekenis van die drievoudige amp van Christus ter sprake:

Vraag: Waarom word hy Chrishus, wat Gesalfde beteken, genoem?

Antwoord: Omdat Hy deur God die Vader bestem en aangestel en met die Heilige Gees gesalf is tot ons hoogste Profeet en Leraar, wat aan ons die 
verborge raad en wil van God aangaande ons verlossing ten volle bekend gemaak het; tot ons enigste Hoëpriester, wat ons met die enige offer van sy liggaam verlos het en met sy voorbidding gedurigdeur by die Vader vir ons intree; tot ons ewige Koning, wat ons met sy Woord en Gees regeer en ons by die verlossing wat verwerf is, beskerm en bewaar.

Ook die voordeel van sy drievoudige amp vir ons word in 'n enkele vraag saamgevat. Die samestellers van die Heidelberger maak in vraag 32 'n pragtige greep:

Vraag: Waarom word jy 'n Christen genoem?

Antwoord: Omdat ek deur die geloof 'n lid van Christus is en daardeur deel aan sy salwing het, sodat ek sy Naam kan bely, myself as 'n lewende dankoffer aan Hom kan toewy en in hierdie lewe met 'n vrye gewete teen die sonde en die duiwel kan stry en hiema met Christus in ewigheid oor alle skepsels kan regeer.

Bogenoemde vergelyking toon Calvyn se invloed: die drievoudige amp van die Middelaar kom by die bespreking van die betekenis van die naam Christus aan die orde. Dit toon egter terselfdertyd die selfstandigheid van die Heidelberger, wat Calvyn se gedagtes op 'n eie, unieke en bondige manier as Skriftuurlik verwoord. Die selfstandigheid van die Heidelbergse Kategismus is nie net sigbaar in die sintese van Calvyn se gedagtes nie maar ook in die omkering van die orde waarin die triplex munus behandel word. Die Geneefse Kategismus praat van Christus as Koning, Priester en Profeet, terwyl die Heidelberger die Middelaar teken as Profeet, Priester en Koning. In die lig van 'n opvoedingsituasie moet 'n mens erken: wat formulering betref, is die Heidelberger los hande voor.

\section{Slot}

Die bespreking van die naam Christus is deel van die uiteensetting van die Tweede Artikel van ons geloofsbelydenis. Ook in ander elemente van die Tweede Artikel van die Apostolicum kan die invloed van Calvyn en van die Geneefse Kategismus op die Heidelberger aangetoon word Hierdie invloed is deur Ursinus bemiddel. In sy behandeling van die geloof in Christus soos vervat in die Catechesis Maior, wat origens weinig invloed op die Heidelbergse Kategismus gehad het, is die invloed van Calvyn sigbaar. Neuser (1979:184) sê:

A. Lang hatte schon für diesen Teil der Catechesis Maior festgestellt: 'Offenbar ist C (Calvins Katechismus) die Hauptquelle'. Dieser Wesenszug ist in Minor und den Heidelberger übernommen worden.

In die Heidelbergse Kategismus word die Tweede Artikel breedvoerig behandel (vr. 29-52). Dit lei tot die konklusie dat, van alle kategismusse wat die kommissie geraadpleeg het, die Geneefse Kategismus waarskynlik die grootste invloed op die Heidelberger gehad het. Maar dan tog 'n invloed van sodanige aard dat die 
Heidelbergse Kategismus sy unieke aard behou het en met sy helderheid en skoonheid van formulering tot vandag 'n geliefde leerboek gebly het.

\section{Literatuurverwysings}

CALVYN, J. 1864-1897. Ioannes Calvini opera quae supersunt omnia. Vol. 19. Ed. Baum, Cunitz \& Reuss. Brunsvigae : Schwetschke et filium (afgekort: OC)

BENOIT, 1957.

kyk

CALVYN, 1957.

CALVYN, J. 1957 Institution de la religion Chrestienne Livre second. Publiée par J-D. Benoit Paris : Librairie Philosophique J Vrin

CALVYN, J. 1981. Calvyn se Kategismus. Vertaal deur H W. Simpson. Potchefstroom Potchefstroomse Teologiese Publikasies (afgekort GK)

CALVYN, J. 1984. Institusie van die Christelike godsdiens (1559), Boek 1. Vertaal deur H.W. Simpson. Potchefstroom : Calvyn Jubileum Boekefonds (=CJBF)

CALVYN, J. 1986. Institusie van die Christelike godsdiens (1559), Boek 2. Vertaal deur H.W. Simpson Potchefstroom : CJBF

CALVYN, J. 1988 Institusie van die Christelike godsdiens (1559), Boek 3 Vertaal deur H W Simpson Potchefstroom : CJBF

ENGELBRECHT, B.J. 1989. 'n Vergelyking tussen die teologie van die Nederlandse Geloofsbelydenis en die Heidelbergse Kategismus. Hervormde Teologiese Studies, 45(3):626-644.

GOETERS, JF.G 1963 Entstehung und Frügeschichte des Kategismus (In Coenen, L., red. Handbuch zum Heidelberger Katechismus. Neukirchen: Neukirchener Verlag p 323.)

HEIDELBERGSE KATEGISMUS. 1987. ( $n$ Die berymde Psalms en Skritberymings. 2de hers. uitg Kaapstad : N G.Kerk-uitgewers p. 521-566.)

HOLLWEG, W 1961. Neue Untersuchungen zur Geschichte und Lehre des Heidelberger Katechismus. Neukirchen : Neukirchener Verlag.

HOLLWEG, W. 1968. Neue Untersuchungen zur Geschichte und Lehre des Heidelberger Katechismus. Zweite Folge Neukirchen : Neukirchener Verlag

LUTHER, M 1912. D Martin Luthers Werke Kritische Gesamtausgabe. Weimar : Bohlaus (=WA).

LUTHER, M. 1919. Dr Martin Luthers Enchiridion. Der kleine Catechismus. (In Schaff, P., ed. The Creeds of Christendom, vol 3. New York: Harper \& Brothers p. 74-92.)

MULLER, E.F.K. 1900. Jesu Christi dreifaches Amt. (In Realencyclopadie für protestantische Theologie und Kirche, 8:733-741.)

NEUSER, W.H. 1979. Die Vater des Heidelberger Katechismus. Theologische Zeitschrifi, 35:177-194

NIESEL, W (Herausg) 1948 Bekenntnisschriften und Kirchenordnungen der nach Gottes Wort reformierte Kirche. 3e dr Zollikon-Zürich : Evangelischer Verlag

OBERHOLZER, J.P 1986. Die Heidelbergse Kategismus Pretoria : Kital

OBERHOLZER, JP. 1989. Die Heidelbergse Kategismus in sy eerste jare Hervormde Teologiese Siudies, 45(3) 598-610

POLMAN, A D R. 1961. Ursinus (In Christelijke Encyclopedie 6:439.)

SCHULZE, L.F. 1971 Calvin's Reply to Pighius Potchefstroom : Pro Rege.

SCHULZE, L.F. 1991. Twee kategismusse uit die sestiende eeu In die Skriflig, 25(1):3-27

STEENKAMP, J J 1989 Ursinus, die opsteller van die Heidelbergse Kategismus, Olevianus en die Heidelbergse teologie Herrormde Teologiese Studies, 45(3):611-625. 
